\title{
Albanon
}

Revistë kulturore

\section{5 vjet nga shfaqja e parë e grupit teatror profesionist Skampa të Elbasanit}

\author{
Fetah Biza
}

Teatri Skampa u krijua në mesin e vitit 1962, si rezultat i zgjerimit të trupave profesioniste nga i gjithë vendi ynë; pas trupave të Teatrit Popullor, të Shkodrës, të Korçës, të Durrësit, të Vlorës dhe atij të Elbasanit. Hapja e Institutit të Lartë të Arteve, u mirëprit edhe në qytetin tonë ku konkuruan studentë të apasionuar pas artit. Ndër studentët e parë elbasanas ishte aktori Tomor Himçi që pas mbarimit të studimeve, emërohet i pari në trupën e teatrit Skampa. Më pas, vit pas viti, emëroren aktorë të tjerë si: Shpëtim Shëmili, Tomorr Shishmani, Veronika Papa, Shpresa Shuteriqi etj.

Themelimi i teatrit Skampa pati prurje edhe aktorë të tjerë joelbasanas si: Ndoc Çefa, Robert Ndrenika, Miho Gjini, Qemal Mehmeti, Sheri Mita, Kujtim Meçe etj., që dhanë një kontribut në fizionominë e këtij teatri. Trupa profesioniste u mbështet nga aktorët amatorë të Lëvizjes Artistike që kishte një traditë shumëvjeçare, si para, ashtu edhe pas çlirimit të vendit. Kjo lëvizje amatore kishte si bërthamë aktorët-arsimtarë si dhe ato të institucioneve të tjera. Në ato vite (para vitit 1962), rivalizonin trupat e arsimit, shëndetësisë dhe Kombinatit të Drurit, që u bënë edhe baza e estradës profesioniste dhe më pas e teatrit profesionist. Përbërja e trupës së re u mbështet tek aktorët Demir Hyskja, Haxhi Sejko, Hasan Mehja, Alush Zajmi, Antoneta Kristo, Arta Luzi, Xheku Koçi, Feride Halimi, Olimbi Dhima, si dhe një stafi më të vjetër si: Hysni Hatipi, Thanas Borodani, Skënder Hoxha, që jo vetëm luanin si aktorë, por mbështetnin lëvizjen amatore si regjisorë. Në shtator të vitit 1962, u hap një kurs disamujor për specializimin e këtyre aktorëve amatorë në aktorë profesionistë, duke u sprovuar në aktrim gjatë një viti, si vit prove. Një ndihmesë qe edhe ardhja nga Shkodra e aktorëve Florenc Shllaku e Vjollca Gega, por që jetën artistike nuk e patën të gjatë për arsyen e luftës së klasave. 


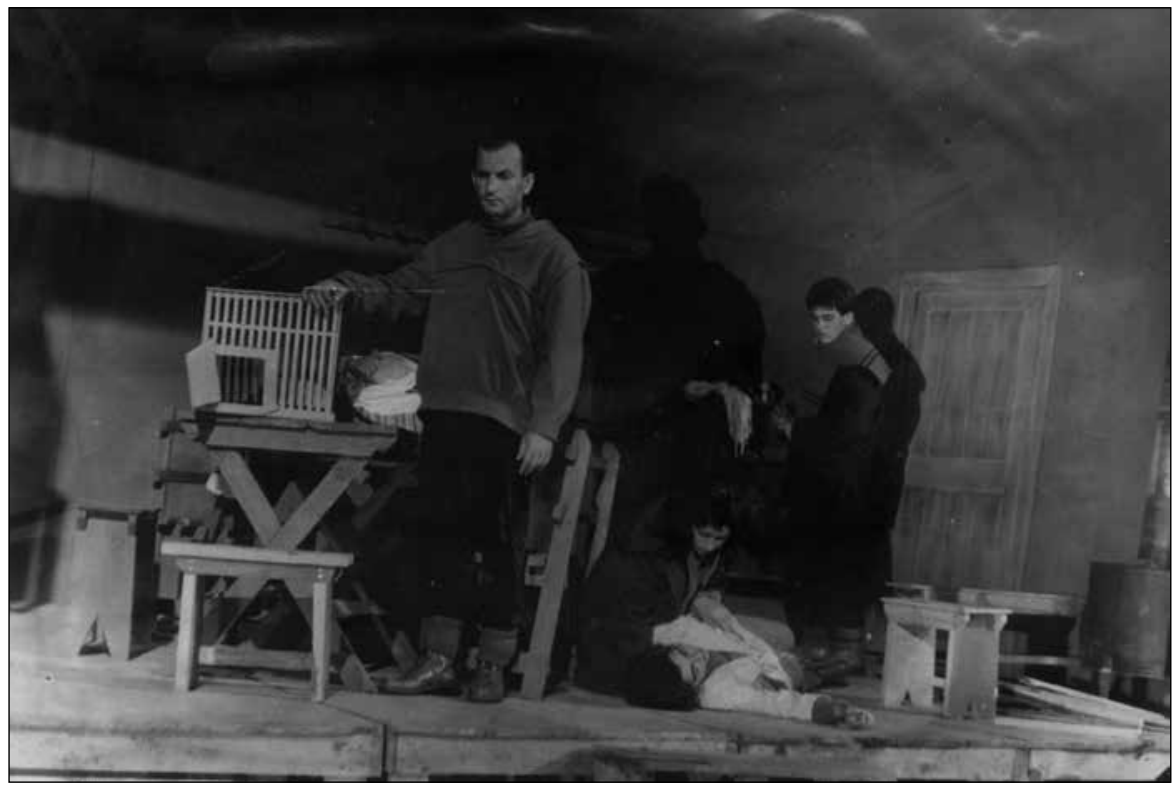

Nga e majta në të djathtë, Thanas Borodani në këmbë, Feride Halimi, Olimbi Dhima Bilali, Ndoc Çefa.

Lind pyetje: teatri profesionist u krijua në vitin 1962 dhe shfaqja e parë u dha më 26 qershor 1963. Pse pas një viti?

Me organizimin e ri dhe krijimin e stafit të teatrit profesionist, u bë një ndarje nga teatri i estradës. Deri në atë kohë shfaqjet e estradës zhvilloheshin si në prova, fuaje, skenë, në godinën e Shtëpisë së Kulturës dhe Krijimtarisë Popullore Elbasan. Në këtë kohë, kinema Labinoti (sot teatri Skampa) ishte duke rikonstruktuar skenën, pasi po bëhej një zgjerim tërësor në të gjithë komponentët, me skenë brenda standardeve, ndriçim funksional, dhomat e zhveshjes poshtë skenës. Gjatë ditës kryheshin punimet dhe mbasdite jepej filmi me orare. Në darkë ngrihej ekrani i filmit dhe hapej skena e teatrit. Ky bashkëpunim midis kinemasë Labinoti dhe teatrit Skampa, vazhdoi deri në ndërtimin e kinemasë së re (projektuar nga arkitektja Valentina Pistoli, në vitin 1966).

Gjatë vitit 1962, Shtëpia e Kulturës Elbasan u përgatit për operetën "Vajza e portokallave" të Ali Abdihoxhës dhe Kol Jakovës, me një masivizim të të gjitha forcave artistike të qytetit me kompozitor Baki Kongolin, dirigjent Mit'hat Stringën ndërsa regjia iu besua Lec Shllakut i ardhur si regjisor profesionist dhe me përvojë që nga Ansambi i Ushtrisë, në teatrin e Shkodrës. Kjo operetë konkuroi në Tiranë me rastin e 50-vjetorit të Shpalljes së Pavarësisë 


\section{Albanon}

\section{Revistë kulturore}

e më pas në Vlorë, Durrës, etj. Me fillimin e vitit 1963, vazhduan provat e shfaqjes "Rrethimi i Bardhë", e cila ishte gati, por pritej mbarimi i punimeve të skenës. Data 26 qershor ishte dita e parë ku trupa profesioniste e teatrit Skampa dha premierën "Rrethimi i Bardhë".

Ja si shkruan kritiku Dionis Bubani me dashamirësi për këtë trupë profesioniste që luajti premierën e parë:

1. Rrethimi i bardhë", vepër e shkrimtarit Naun Prifti, është një dramë aktuale që pasqyron ndjenjat, mendimet dhe vet-mohimin e njerëzve të rinj. Ajo është nje vepër psikologjike një dramë mendimesh që të kujton pjesët e Çehovit në kuptimin e mirë të fjalës, ku personazhet zhvillohen jo nëpërmjet rrugës së lehtë të efekteve të jashtme, por në sajë të karakterit të tyre që skalitet me mjeshtëri, në aksion e sipër, gjatë zhvillimit të dramës.

Pak personazhe veprojnë në këtë dramë, por ato mbeten të paharruara.

Kjo dramë është vënë në skenë me sukses për herë të parë nga kolektivi i Teatrit Profesionist të Elbasanit.

Regjizori Lec Shllaku, i cili deri më sot vuri në skenë me sukses aq pjesë nacionale dhe të huaja, tregoi përsëri talent dhe zotësi. Duke punuar me dashuri me një kolektiv dhe me një dramaturg të ri, ay arriti të na japë një shfaqje realiste, tërheqëse, të pastërt ku veprojnë të gjallë heronjtë e ditëve tona, me të mirat dhe të metat e tyre. Ndoshta nuk gaboj po të shpreh mendimin se ka qenë një fat i madh për teatrin e ri të Elbasanit të ketë në gjirin e tij, në hapat e para, një regjizor të sprovuar, me një provë aq të gjatë në lëmin e artit teatral.

Natyrisht çdo fillim, krahas suksesit, ka edhe të meta, për shëmbëll, në shfaqjen e ardhshme të dramës do dëshironim të shikonim në skenë një Lizë, e cila t’a fillojë rolin e saj me një ritëm më të gjallë, të komunikojë më shpejt me spektatorin, gjë të cilën e arrin më lehta aktorja Olimbi Dhima, që interpreton rolin e Merit, e shoqes së Lizës.

Thanas Borodani paraqitet mirë në rolin e Bashkimit, por krahas anës zyrtare ay duhet të thellohet më tepër për t'a zbërthyer rolin duke gjetur edhe Bashkimin - njeri me ndjenja të forta, që dashuron mjeken e re. Ndërsa del e qartë figura e tij si organizator $i$ aftë, si njeri i guximshëm që përballon çdo situatë, nuk na paraqitet me të njejtën forcë edhe në botën e ndjenjave imtime.

Efraim Gashi, për mendimin tim - realizoi një Fred që i avitet mjaft të dhënave të autorit. Me lojën e tij të shkathët ay tregon karakterin e tij të ulët. Filloi dramën i qeshur, i dashur dhe mbaron i neveritshëm. Ay të bind me lojën e tij të natyrshme. 


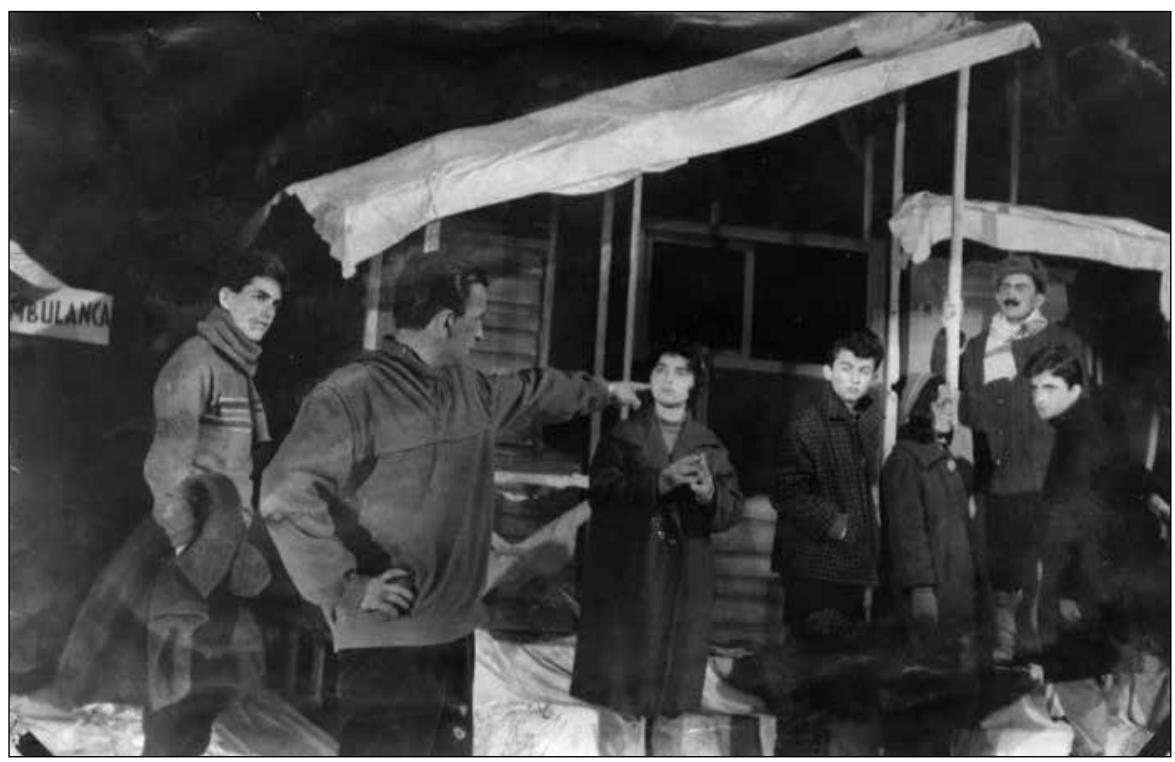

nga e majta në të djathtë, Ndoc Çefa, Thanas Borodani, Olimbi Dhima Bilali, Dhimosten Papa, Feride Halimi, Efraim Gashi, Skënder D. Hoxha

Ndoc Çefa në rolin e entusiaztit është figurë tërheqëse në skenë, por ai duhet të ruhet që të mos teatralizojë disa herë entisiazmin e tij, i cili sa më natyrshëm të duket aq më real do tingëllojë në skenë.

Skënder Hoxha, në rolin e magazinierit, Demir Hyskja në rolin e shoferit dhe Dhimosten Papa në atë të Avniut, e kryen mirë detyrën e tyre.

Por pak verejtje nuk e zvogëlojnë suksesin e merituar që korri teatri profesionist i Elbasanit, $i$ cili pa dyshim në të ardhmen do të na dhurojë shfaqje më të ngritura. Por gjithmonë artdashësi elbasanas do t'a kujtojnë me respekt dramën e bukur, me dinjitet artistik "Rrethimi i bardhë", që inagurojë teatrin profesionist dhe shënoi lindjen e një dramaturgut të ri shqiptar.

Vlerësime të mira jep edhe regjisori i Estradës së Ushtarit Gjon Daka:

2. Mbrëmja e 26 qershorit do të mbetet në kujtesën e amatorëve të qytetit të Elbasanit, një ndër datat më të rëndësishme të jetës së tyre artistike: u dha shfaqja e parë e të parit theatër profesionist të qytetit, vepra e parë dramatike e shkrimtarit Naun R. Prifti, në skenën e re të theatrit, një ndër më të mirat e vendit tonë, ku debutuan për herë të parë në theatër 7 nga 9 personazhet e dramës, në regjinë e Lec Shllakut. Qe një festë artistike, emocionuse: spektatorët e të ftuarit prisnin se si do ta sillte në skenë fjalën artistike kjo trupë, me gjithë vapën e madhe, dridheshin: si do na presin. 


\section{Albanon}

\section{Revistë kulturore}

Të gjykosh mbi punën e një kolektivi të ri që sapo hyri në rradhët e 5 theatrove profesioniste të vendit, është mjaft e vështirë, për vetë faktin se prova e parë shpesh nuk është gjë që përcakton drejt edhe perspektivën e tij. Por duke dalë nga salla e shfaqjes, ne muarëm përshtypje të mira, dhe u bindëm se u gjetëm ballë për ballë me një trupë theatrale, e cila i ka të gjitha forcat e mundësitë për të përballuar edhe prova të tjera më të vështira........

$\mathrm{Një} \mathrm{pjesë} \mathrm{e} \mathrm{personazheve} \mathrm{janë} \mathrm{goditur.} \mathrm{Të} \mathrm{mbetet} \mathrm{në} \mathrm{mendje} \mathrm{figura} \mathrm{e} \mathrm{dashur}$ e "entuzjaztit", këtij të riu që është përfaqësues i denjë i rinisë sonë, që kontriboi në kaqë shumë vepra të ndërtimit të vendit. Aktori Ndoc Çefa e dha bukur figurën e këtij të riu. Ne pamë edhe në figurën e shoferit Pili (aktori Demir Hyskja) një njeri të dashur e të sakrificës, një nga ata shoferë që dijnë të punojnë, që marrin pjesë tërësisht në fatin e kolektivit. Po ashtu Avniu (aktori Dhimosten Papa), flegmatik indiferent, magazinieri Latif (aktori Skënder Hoxha) servil e frikacak, u trajtuan me mjaft natyrshmëri. Meri (aktorja Olimbi Dhima) u trajtua me mjaft shkathtësi e ndjenjë. Por mbi tre personazhet kryesorë do të ndalohemi pak më gjatë. Te Liza (aktorja Feride Halimi) ne pamë mjeken e re të vendosur në misionin e saj, dashnoren e lëkundëshme, vajzën që akoma nuk i ka njohur njerëzit, që nuk e kupton menjëherë se cili mund t’i sjelli lumturinë në jetë. Ajo e dha drejtë gjëndjen shpirtërore të një grueje që jeton në mes të dy njerëzish: të atij që dikur e ka dashur dhe vazhdon ta dojë dhe të atij tjetrit, që kjo është gati të bëjë çdo gjë për të. Por me të gjitha këto të dhëna të brendëshme, ajo, për diapazonin shumë të ngushtë të zërit, nuk arriti të komunikojë me spektatorin. Ndofta ajo nuk është Liza që kërkohet dhe nuk i ndihmon aqë sa duhet partnerët e saj.

Tek Fredi, inxhinieri i ri (aktori Efreim Gashi) pamë një aktor me talent, me një diksjon të pastër, të natyrshëm, por që ka nevojë për më shumë shkathtësi dhe që në rolin e tij duhet të punojë më shumë që atë figurë simpatike të çasteve të para, ta bëjë të neveritshme kur, për të shpëtuar lëkurën, braktis shokët. Ai duhet të mundohet që të zbresi pikërisht nëpër atë rrugë që duhet të ngrihet Bashkimi (aktori Thanas Borodani), i cili në fillim duhet të na japë përshtypjen se ka ardhur t’i prishë lumturinë çiftit të ri, ndërsa me veprimtarinë e tij të mëvonshme të ngrihet dhe të bëhet figura më e dashur, njeriu më i dhimbëshëm, heroi i ditëve tona.

Do të mendonim se disa të meta të rregullueshme si në fillim ashtu edhe në fund të shfaqjes së parë mund të evitohen, si trajtimi i monologjeve me izolim drite sidomos i atyre të Bashkimit, izolimi i mjekes Liza në skenën PiloMeri, trajtimi më i kujdesshëm i anës muzikale, sidomos gjatë intervaleve dhe kryesisht një ritëm më i shpejtë i shfaqjes. 


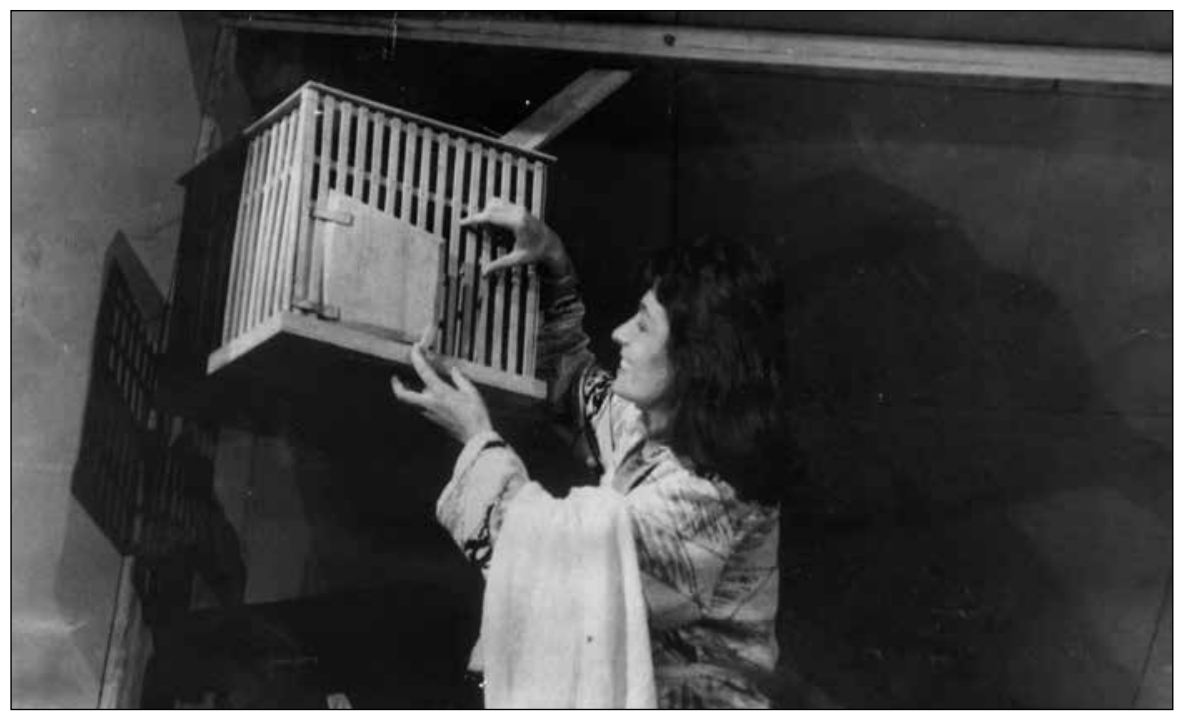

Feride Halimi

Por këto nuk e ulin vlerën e shfaqjes si dhe kolektivit ashtu edhe regjisë i bie merita e madhe që solli në skenën tonë një shfaqje të denjë e me dinjitet artistik.

Ja si e vlerëson edhe studenti, më pas aktori dhe drejtori i parë i Teatrit "Skampa", Miho Gjini

3. Subjekti i dramës "Rrethimi i bardhë" paraqet një material shumë të pasur e shumë interesant për një dramë realiste të ditëve tona, ku veprimet e personazheve jepen më tepër në planin psikologjik. Për autorin tonë, rëndësinë më të madhe e kanë mendimet e njerëzve, veprimet, ndryshimet e karaktereve të tyre e jo aq kushtet gjeografike, vërtetësia e rrethanave; ai qëllimisht i vë personazhet në një provë të vështirë për të diferencuar karakterin e njerëzve, për të evidentuar pastaj figurën e ndritur të njeriut të vërtetë dhe përfundimisht të nxjerrë në pah shpirtin e kolektivitetit, forcën e madhe të një grupi njerëzish, të cilët mund t'i rezistojnë jo vetëm lodhjes fizike, urisë dhe dëborës, po edhe vdekjes. Këtu rreh edhe çekani i autorit, synimi i tij më i lartë artistik.

Rruga e teatrit është e gjatë dhe sivjet ajo mbushi 55 vjet si trupë profesioniste. I urojmë kësaj trupe jetë sa më të gjatë që të mos humbin traditat artistike profesioniste të këtij qyteti që ishte ndër të parët që ngriti Shoqëri Teatrale me status që në vitin 1918 dhe ky është viti 100 i lëvizjes amatore dhe 55 vjetori i krijimit të trupës profesioniste në Elbasan. 


\section{Albanon}

\section{Revistë kulturore}

Tematika e teatrit: dramë

\begin{tabular}{|c|l|l|}
\hline $\mathrm{Nr}$ & Emri i dramës & Rrethimi i bardhë. ( 26 qershor 1963 ) \\
\hline 1 & Drejtori Teatrit & \\
\hline 2 & Dramaturg & Naun Prifti \\
\hline 3 & Vu në skenë nga: & Lec Shllaku, /as. Thoma Kristo \\
\hline 4 & Piktor & Agim Zajmi \\
\hline 5 & Zbatues dekori & Zyhdi Bejtja \\
\hline 6 & Operator ndriçimi + zëri & Xhevdet Qatipi \\
\hline 7 & Rekuizitier - Garderobier & Ali Luzi \\
\hline 8 & Rrobaqepës & Janaq Xhufka \\
\hline 9 & Marangoz + punëtor skene & Anastas Toçi, Petrit Tabaku \\
\hline 10 & Inspektor skene & Haxhi Sejko \\
\hline
\end{tabular}

\begin{tabular}{|c|c|c|c|}
\hline $\mathrm{Nr}$ & Personazhet & Roli & Aktori që interpreton \\
\hline 1 & Liza & mjeke e re & Feride Halimi - Arta Luzi - Bukuri Xhoxhi \\
\hline 2 & Meri & teknike e mesme & Olimbi Dhima (Bilali) - Englantina Stafa \\
\hline 3 & Fredi & inxhinier & Efreim Gashi - Thoma Kristo \\
\hline 4 & Latifi & magazinier & Skënder D. Hoxha - Hysni Hatipi. \\
\hline 5 & Entuziasti & teknik & Ndoc Çefa \\
\hline 6 & Bashkimi & inxhinier & Thanas Borodani - Kadri Roshi. \\
\hline 7 & Avniu & teknik i mesëm & Dhimosten Papa - Hasan Mehja. \\
\hline 8 & Pilo & shofer & Demir Hyskja (A.P) \\
\hline 9 & & një malësor & Alush Zajmi \\
\hline A) & \multicolumn{3}{|c|}{$\begin{array}{l}\text { Me pak fjalë rreth përmbajtjes } \\
\text { Në Valmure ( diku në veri ) pak vjet më parë..... } \\
\text { Një grup inxhinierësh dhe teknikësh shkojnë atje për ndërtimin e një fabrike. Në mes të tyre është } \\
\text { edhe Liza, mjeke, vajzë e kohës. Ajo ndodhet bashkë me Fredin, të fejuarin e vet, inxhinier. Rastis që në } \\
\text { këtë kantier vjen edhe inxhinieri Bashkim Krasta, i fejuari i parë i Lizës. } \\
\text { Kjo rastisje i shqetëson të tre. Bile Fredi bahet xheloz dhe do përpiqet që të largohet. } \\
\text { Por shqetësimi shtohet dhe arrin kulmin. Bora e izoloi papritmas kantierin dhe maqina, që sillte } \\
\text { rezervat ushqimore të dimrit u përmbys. Këtu fillojnë fatkeqësitë. Kolektivi i vogël e humbet } \\
\text { kompätësinë. I trembur nga frika dhe xhelozia, Fredi kërkon të izolojë përgjegjësinë nga } \\
\text { kolektivi dhe ikën. Por Bashkimi, që ishte edhe partizan, duke pasë eksperiencën e borës dhe } \\
\text { n’anën tjetër, duke shpresuar në ndihmën e afërme nga qendra, ngul këmbë që të mos i shkojnë } \\
\text { drejt vdekjes, aq më tepër që shoferi Pilo dergjet në shtrat i sëmurë rëndë. Por Fredi s'heq dorë nga } \\
\text { ikja, pranon të braktisë edhe Lizën, së cilës si mjeke, ndërgjegjja nuk e lejon të largohet nga shoku i } \\
\text { sëmurë rëndë. Fredi, Avniu, Latifi ikin. Fati i tyre nuk dihet. Ndoshta ata u shqyen nga ujqit. } \\
\text { Gjendja në kantjer keqësohet aqë, sa që rezerva e fundit është një patate, të cilën Meri e ka ruajtur } \\
\text { për të dashurin e vet, Pilon. Vdekja kërcënon pesëshen e fundit. Atëhere Bashkimi, për të shpëtuar } \\
\text { shokët, vendos të shkojë në fshat. Por ai s'kthehet i gjallë. Në vend të tij vijnë fshatarët me bukë } \\
\text { dhe ushqime. }\end{array}$} \\
\hline
\end{tabular}




\section{Literaturë:}

- Fleta volant e shfaqjes.

- Revista "Ylli", gusht 1962 nga Dionis Bubani.

- Gazeta "Drita", Shfaqja e parë e një teatri të ri, nga Gjon Daka, 30. 06. 1963.

- Gazeta "Drita", Mendime rreth dramës "Rrethimi I Bardhë", i Naun Priftit; nga Miho Gjini, 30. 06. 1963. 